\title{
Modeling landscape-scale pathogen spillover between domesticated and wild hosts: Asian soybean rust and kudzu
}

\author{
Anna M. Fabiszewski, James Umbanhowar, and Charles E. Mitchell ${ }^{1}$ \\ University of North Carolina at Chapel Hill, Department of Biology, CB \#3280 408, Coker Hall, \\ Chapel Hill, North Carolina 27599-3280 USA
}

\begin{abstract}
Many emerging pathogens infect both domesticated and wild host species, creating the potential for pathogen transmission between domesticated and wild populations. This common situation raises the question of whether managing negative impacts of disease on a focal host population (whether domesticated, endangered, or pest) requires management of only the domesticated host, only the wild host, or both. To evaluate the roles of domesticated and wild hosts in the dynamics of shared pathogens, we developed a spatially implicit model of a pathogen transmitted by airborne spores between two host species restricted to two different landscape patch types. As well as exploring the general dynamics and implications of the model, we fully parameterized our model for Asian soybean rust, a multihost infectious disease that emerged in the United States in 2004. The rust fungus Phakopsora pachyrhizi infects many legume species, including soybeans (Glycine max) and the nonnative invasive species kudzu (Pueraria montana var. lobata). Our model predicts that epidemics are driven by the host species that is more abundant in the landscape. In managed landscapes, this will generally be the domesticated host. However, many pathogens overwinter on a wild host, which acts as the source of initial inoculum at the start of the growing season. Our model predicts that very low local densities of infected wild hosts, surviving in landscape patches separate from the domesticated host, are sufficient to initiate epidemics in the domesticated host, such that managing epidemics by reducing wild host local density may not be feasible. In contrast, managing to reduce pathogen infection of a domesticated host can reduce disease impacts on wild host populations.
\end{abstract}

Key words: Asian soybean rust fungus; Glycine max; infectious disease; kudzu; multihost pathogen; nonnative invasive species; pathogen spillover; Phakopsora pachyrhizi; Pueraria montana var. lobata; seasonality; $S-I$ model.

\section{INTRODUCTION}

Emerging infectious diseases can have strong effects on public health, agricultural production, and the dynamics of wild populations, including those of conservation concern (Daszak et al. 2000, Anderson et al. 2004). Intrinsic to emerging diseases is their potential to spread beyond a local host population (Riley 2007). Transmission at the landscape scale (i.e., among multiple local populations distributed among patchy habitat types) is an important link between local host populations and the regional metacommunity (Plantegenest et al. 2007, Real and Biek 2007). Most pathogens infect more than one host species (Power and Mitchell 2004, Gilbert and Webb 2007), creating the potential for pathogen spillover, whereby a pathogen is transmitted from a "reservoir" host population (one that sustains a relatively high pathogen population density) to a nonreservoir host population (Daszak et al. 2000, Power and Mitchell 2004). Pathogen spillover results in apparent competition when it negatively impacts the

Manuscript received 30 April 2008; revised 21 April 2009; accepted 20 May 2009. Corresponding Editor: S. M. Altizer.

${ }^{1}$ Corresponding author. E-mail: mitchell@bio.unc.edu non-reservoir host population (Holt and Pickering 1985, Hudson and Greenman 1998, Power and Mitchell 2004).

Many multihost pathogens can be transmitted between landscape patches. For example, in western North America, the bacterium Brucella abortus (cause of brucellosis) is transmitted between cattle, bison, and elk at reserve boundaries (Dobson and Meagher 1996). Severity of sudden oak death (caused by the oomycete Phytophthora ramorum) on oaks and tanoaks varied across a California landscape, depending on vegetation composition and microclimate (Condeso and Meentemeyer 2007). To effectively model the dynamics of such pathogens requires incorporating both multihost dynamics and landscape-scale transmission.

Several models of multihost pathogens (Gog et al. 2002, McCallum and Dobson 2002, McCallum et al. 2005) have predicted that spillover between habitat patches can extirpate a host species from the landscape (but see Dobson and Meagher 1996). Because many pathogens are shared among wild and domesticated (e.g., agricultural) hosts, spillover between them may be common (Gilbert and Hubbell 1996, Daszak et al. 2000, Power and Mitchell 2004). In addition, domesticated populations are generally subsidized to maintain them at 
high local densities, often over large portions of the landscape (Power and Mitchell 2004), and their population densities are largely decoupled from negative impacts of disease. Further, high host local densities increase transmission of many pathogens (Gilbert 2002), and wide distribution through a landscape may increase contact with, and pathogen spillover to, wild host populations. On the other hand, wild host populations can also serve as pathogen reservoirs and cause landscape-scale spillover to domesticated populations. Wild animal dispersal can link separate populations of domesticated animals (Dobson and Meagher 1996, Woodroffe et al. 2006). Wild plants growing in uncultivated patches can act as temporal reservoirs, sustaining pathogen populations between agricultural growing seasons (Plantegenest et al. 2007). Thus, it is important to evaluate the potential for spillover in both directions between wild and domesticated host populations (Daszak et al. 2000, Woodroffe et al. 2006).

To investigate these dynamics, we used two spatially implicit models of a pathogen transmitted by airborne spores between two host species: a crop that is restricted to agricultural patches, and a wild plant that is restricted to nonagricultural patches. The "nonseasonal" model allows some analysis. The "seasonal" model examines the effects of pathogen winter survivorship on epidemics. We use our models to address four questions. How is pathogen transmission modulated by the epidemiological traits and landscape abundance of host species, and by the dispersal of pathogen propagules? Can management of pathogen infection in a domesticated population prevent pathogen-induced extinction of a wild population? What is the functional relationship between the quantity of pathogen inoculum overwintering on a wild host and subsequent epidemic size in a domesticated host? How can seasonal shifts in pathogen transmission between two host populations allow large-scale persistence of a pathogen? As well as exploring the general dynamics of the models, we fully parameterized our models for Asian soybean rust, a multihost infectious disease that has emerged in the United States since 2004 (Christiano and Scherm 2007), in order to examine ecological processes in the context of an economically costly crop disease.

\section{Methods \\ Development of the nonseasonal model}

To examine the dynamics of a pathogen infecting both a domesticated (e.g., agricultural) and a wild species, we develop a spatially implicit two-host model of pathogen transmission, following the basic framework introduced by Holt and Pickering (1985), Dobson and Meagher (1996), and McCallum et al. (2005). The model assumes that each host species is restricted to a different landscape patch type (e.g., crop fields and unmanaged vegetation). Thus, they do not compete for resources, but a shared pathogen can be transmitted between them. In this S-I compartment model, each unit of host biomass is regarded as infected $(I)$ or susceptible $(S)$. The system is represented by four differential equations, where domesticated (i.e., agricultural) populations and parameters are denoted by a subscript "a" and wild hosts by a subscript "w":

$$
\begin{aligned}
& \frac{d S_{\mathrm{a}}}{d t}=\delta_{\mathrm{a}} I_{\mathrm{a}}+\left(a_{\mathrm{a}}-b_{\mathrm{a}}-\lambda_{\mathrm{a}}\right) S_{\mathrm{a}} \\
& \frac{d I_{\mathrm{a}}}{d t}=\lambda_{\mathrm{a}} S_{\mathrm{a}}-\left(\alpha_{\mathrm{a}}+b_{\mathrm{a}}\right) I_{\mathrm{a}} \\
& \frac{d S_{\mathrm{w}}}{d t}=\left(\delta_{\mathrm{w}} I_{\mathrm{w}}+a_{\mathrm{w}} S_{\mathrm{w}}\right)\left(1-\frac{N_{\mathrm{w}}}{K_{\mathrm{w}}}\right)-b_{\mathrm{w}} S_{\mathrm{w}}-\lambda_{\mathrm{w}} S_{\mathrm{w}} \\
& \frac{d I_{\mathrm{w}}}{d t}=\lambda_{\mathrm{w}} S_{\mathrm{w}}-\left(\alpha_{\mathrm{w}}+b_{\mathrm{w}}\right) I_{\mathrm{w}} .
\end{aligned}
$$

In Appendix $\mathrm{A}$, we derive expressions for $R_{0}$ (the basic reproductive rate) for the full two-host species model, and for each host species alone. Our derivations follow the analysis of Dobson (2004), who considered a special case of the general model derived by Diekmann et al. (1990).

While this model formulation is general beyond plants, we parameterize (Table 1) and interpret the local densities of hosts ( $S_{x}$ and $I_{x}$ for susceptible and infected hosts, respectively) in terms of host leaf biomass $\left(\mathrm{g} / \mathrm{m}^{2}\right)$. These local densities are within occupied landscape patches. The proportion of the landscape occupied by each host species is modeled as part of the transmission coefficients. The domesticated population is assumed to remain at constant local density, reflecting subsidy by humans. In the wild host, we assume logistic growth. Lambda $(\lambda)$ is the relative rate at which susceptible biomass becomes infected (i.e., the force of infection; see Eq. 2). Susceptible host biomass is produced by growth of infected host biomass at rate $\delta$, and by growth of susceptible host biomass at rate $a$. Both susceptible and infected host biomass experience a constant loss rate $(b)$, and infected host biomass experiences an additional loss rate to disease $(\alpha)$. Once biomass becomes infected, it does not recover.

The force of infection for host species $i$ is

$$
\lambda_{i}=\sum I_{j} \beta_{i j}
$$

In this equation, $\beta_{i j}$ represents the transmission coefficients, where $i$ is the host species receiving transmission and $j$ is the source of transmission. Thus, for infection of each host species, there are two transmission coefficients, one for transmission from conspecifics, and one for transmission from heterospecifics. The transmission coefficients incorporate implicit landscape structure so that transmission from heterospecifics occurs only between habitat patches, while transmission from conspecifics can be either within a patch or between patches. This represents a landscape in which each landscape patch is occupied by at most one host species 
TABle 1. Parameters used in model simulations, based on soybeans, Glycine max (domesticated host), kudzu, Pueraria montana var. lobata (wild host), and Asian soybean rust, Phakopsora pachyrhizi (pathogen) in the southeastern United States.

\begin{tabular}{|c|c|c|c|c|}
\hline \multirow[b]{2}{*}{ Parameter } & \multirow[b]{2}{*}{ Units } & \multirow[b]{2}{*}{ Definition } & \multicolumn{2}{|c|}{ Value used in model $\uparrow$} \\
\hline & & & $\begin{array}{l}\text { Domesticated } \\
\text { host }\end{array}$ & $\begin{array}{l}\text { Wild } \\
\text { host }\end{array}$ \\
\hline$N$ & $\mathrm{~g} / \mathrm{m}^{2}$ & total host local density & $\begin{array}{c}400 \\
(150-500)\end{array}$ & not constant \\
\hline$K$ & $\mathrm{~g} / \mathrm{m}^{2}$ & carrying capacity & 400 & $1291 \S$ \\
\hline$a$ & $t^{-1}$ & growth rate of uninfected hosts & $1 \ddagger$ & 6.7 \\
\hline$\delta$ & $t^{-1}$ & growth rate of infected hosts & $1 \ddagger$ & 6.7 \\
\hline$b$ & $t^{-1}$ & loss (mortality) rate of uninfected hosts & $1 \ddagger$ & 4.35 \\
\hline$\alpha$ & $t^{-1}$ & additional loss (mortality) rate of infected hosts & 0 & $0-3.5$ \\
\hline$p$ & spores $\cdot$ lesion $^{-1} \cdot \mathrm{yr}^{-1}$ & pathogen spore production rate & \multicolumn{2}{|c|}{$\begin{array}{c}4666 \\
(500-6600)\end{array}$} \\
\hline$d$ & & proportion of spores not lost within the patch & \multicolumn{2}{|c|}{0.326} \\
\hline$\varepsilon$ & & proportion of landscape area occupied by the host & $\begin{array}{c}0.125 \\
(0.04-0.4)\end{array}$ & $\begin{array}{c}0.0125 \\
(0-0.06)\end{array}$ \\
\hline$l$ & & proportion of spores that escape into the atmosphere & \multicolumn{2}{|c|}{0.122} \\
\hline$m$ & & proportion of spores that survive UV radiation during transport & \multicolumn{2}{|c|}{0.295} \\
\hline$\gamma$ & $\mathrm{m}^{2} / \mathrm{g}$ & spore infectivity relative to host local density & \multicolumn{2}{|c|}{$\begin{array}{c}0.258 \\
(0.046-0.471)\end{array}$} \\
\hline$g$ & lesions/spore & spore germination success & \multicolumn{2}{|c|}{$\begin{array}{c}0.6 \\
(0.05-0.85)\end{array}$} \\
\hline$A$ & $\mathrm{~g} \cdot \mathrm{m}^{-2} \cdot$ lesion $^{-1}$ & lesion biomass density & $1.35 \times 10^{-11}$ & $1.59 \times 10^{-10}$ \\
\hline
\end{tabular}

Notes: Values in parentheses are the range examined in estimation of $R_{0}$ and/or numerical simulations. $R_{0}$ is the number of secondary infections produced by the initial infection in a host population.

$\uparrow$ See Appendix D for the estimation of parameter values from empirical data.

$\$$ For the domesticated host species, growth and loss rates were all set to $1 / t$, where $t$ is in years, to simulate the annual planting and harvesting of a cultivated crop.

$\S$ This value was set to give the empirically reported equilibrium local density of $N_{\mathrm{w}}=453 \mathrm{~g} / \mathrm{m}^{2}$.

(e.g., where one host is restricted to agricultural patches and the other is restricted to nonagricultural patches).

The transmission coefficients $\beta_{i j}$ include the biological details of transmission:

$$
\beta_{i j}=\frac{p_{j} d_{j} T_{i j} \varepsilon_{i} \gamma_{i} g_{i} A_{i}}{A_{j}\left[1+\gamma_{i}\left(S_{i}+I_{i}\right)\right]} .
$$

Pathogen transmission is assumed to occur via an infective stage that disperses passively and quickly relative to host population dynamics (e.g., an airborne fungal spore). By infecting a susceptible host, each spore can grow into a lesion, which is a mature individual pathogen. The number of lesions in the host population is the local density of infected host biomass $\left(I_{j}\right.$; Eq. 2$)$ divided by the lesion biomass density $\left(A_{j}, \mathrm{~g} \cdot \mathrm{m}^{-2} \cdot\right.$ lesion $\left.^{-1}\right)$.

Each lesion is assumed to produce spores at rate $p$. Of these spores, some fall onto the ground or onto a plant that is not a host within the same landscape patch, leaving a fraction $\left(d_{j}\right)$ that can play a role in transmission. Of this fraction, a proportion $\left(l_{j}\right)$ escapes the plant canopy of the landscape patch into the atmosphere. Spores that escape the canopy into the atmosphere experience mortality from UV radiation, with a fraction $\left(m_{j}\right)$ surviving. The parameters $l_{j}$ and $m_{j}$ are included in $T_{i j}$ as follows. Susceptible biomass of host species $i$ can be infected by transmission from either infected conspecific hosts $(i=j)$ or infected heterospecific hosts $(i \neq j)$. Transmission from conspecifics can either be from within the same patch or from a different patch. Thus, $T_{i j}=1-l_{j}+l_{j} m_{j}$ for transmission from conspecifics, where the quantity $\left(1-l_{j}\right)$ is the proportion of spores that did not escape the patch into the atmosphere. Because each patch contains at most one host species, transmission from heterospecifics must be from spores that escaped into the atmosphere from a different landscape patch. Thus, $T_{i j}=l_{j} m_{j}$ for transmission from heterospecifics.

Spores are assumed to be deposited in landscape patches containing the domesticated host or the wild host, in proportion to their respective host landscape abundances $\left(\varepsilon_{i}\right)$. A fraction $\left(1-\varepsilon_{\mathrm{a}}-\varepsilon_{\mathrm{w}}\right)$ are lost to patches lacking a host. For spores that fall within a given landscape patch occupied by a host, a fraction, $\gamma_{i}$, are deposited on a host leaf surface. To constrain each spore to be deposited and form a lesion only once, we include a term $\left[1+\gamma_{i}\left(S_{i}+I_{i}\right)\right]$ in the denominator of Eq. 3. This term also represents the reduction in infection rates caused by spores being deposited on previously infected hosts. The proportion of deposited spores that successfully germinates and produces a new infective lesion is given by $g_{i}$. The product of all the above yields the instantaneous change in the number of lesions, which is scaled into change in infected biomass by the lesion biomass density of the host species that is becoming infected $\left(A_{i}\right)$.

\section{Biology of the hosts and pathogen}

Asian soybean rust is caused by the fungus Phakopsora pachyrhizi, which infects at least 93 legume species (Slaminko et al. 2008). P. pachyrhizi is an obligate 
parasite that is transmitted by airborne spores that can infect leaves and herbaceous stems. After infection there is a two-week latent period, followed by the appearance of local (not systemic) lesions. Typically, each lesion is an individual fungal organism that asexually produces a mean of 4666 uredospores over the following few weeks, then dies as leaf resources are depleted (Melching et al. 1979). While $P$. pachyrhizi can produce teleospores that could allow a sexual cycle, a sexual cycle has never been observed (Bonde et al. 2008). Because its functional life cycle includes only uredinial lesions and uredospores, neither of which can survive extended freeze periods (Jurick et al. 2008, Park et al. 2008), and spore dispersal from fallen dead leaves is limited (Jurick et al. 2008, Park et al. 2008), it is geographically restricted in winter to areas protected from freezes. In the United States, it has only been observed to overwinter in Texas and Florida (Pivonia and Yang 2004, Jurick et al. 2008) but is expected to also overwinter elsewhere along the Gulf Coast (Park et al. 2008). P. pachyrhizi was discovered in 1902 in Japan. Between 1934 and 1951, it spread to Australia, China, and India. By 1997, it spread to Africa, then to South America in 2000 (Schnepf 2005). In 2004, it was first reported in the continental United States. While an average $25 \%$ yield loss is predicted for untreated infected soybean fields in the United States (Yang 1995, Roberts et al. 2006), how widespread infection will be has been difficult to predict (Pivonia et al. 2005).

Of the hosts for $P$. pachyrhizi, we consider soybeans (Glycine $\max$ [L.] Merr.) and the nonnative invasive species kudzu (Pueraria montana (Lour.) Merr. var. lobata (Willd.) Maesen \& S. Almeida). Kudzu is thought to be the chief overwintering host for P. pachyrhizi in North America (Christiano and Scherm 2007, Bonde et al. 2008). We estimated kudzu landscape abundance based on a survey in North Carolina, in which kudzu occupied an average of $2.4 \% \pm 0.25 \%$ of edges sampled (Merriam 2003). In a landscape consisting of $52 \%$ edge habitat, this corresponds to a landscape abundance of $1.25 \%$. For soybeans, we calculated landscape abundance for the 15 soy-producing states where soybean rust was reported through 2006 by taking the acreage in soy production as a percentage of the each state's total area. In these states, 2006 landscape abundance of soybeans ranged from $0.1 \%$ to $27.5 \%$ (National Agricultural Statistics Service 2006). In soy-producing counties in North Carolina, the average landscape abundance of soybeans is $12.5 \%$ (U.S. Census Bureau 2002, Toth et al. 2005). We used this value because it is in the middle of the range of soybean landscape abundance in soy-producing states. Additionally, lateplanted soybeans in the southern United States may be at greatest risk of infection by $P$. pachyrhizi (Pivonia and Yang 2006).

Soybean local density $\left(N_{\mathrm{a}}=S_{\mathrm{a}}+I_{\mathrm{a}}\right)$ in the model was fixed at the empirically estimated biomass at crop maturity of $400 \mathrm{~g} / \mathrm{m}^{2}$ (Ball et al. 2000). This assumption was implemented by setting the additional loss rate of infected soy $\left(\alpha_{\mathrm{a}}\right)$ equal to zero, and setting the growth rates of susceptible and infected soy $\left(a_{\mathrm{a}}\right.$ and $\left.\delta_{\mathrm{a}}\right)$, and the loss rate of susceptible soy $\left(b_{\mathrm{a}}\right)$ to all equal $1 / t$, where $t$ is in years. Annualizing these parameters simulates the annual planting and harvesting of the crop.

Carrying capacity of the wild host population, $K_{\mathrm{w}}$, was set to yield an equilibrium host density equal to the average density of leaf biomass in a kudzu stand that had been undisturbed for 15 years (Tsugawa et al. 1993). Data on total aboveground biomass (Tsugawa et al. 1993) were converted to leaf biomass based on an estimate that kudzu leaf biomass is $55 \%$ of total aboveground biomass (Sasek and Strain 1988).

An extensive literature search yielded no references on the effect of $P$. pachyrhizi on kudzu growth and loss rates. Therefore, we assume that the pathogen has a negligible effect on kudzu growth rate $\left(\delta_{\mathrm{w}}=a_{\mathrm{w}}\right)$. Except when we explicitly vary the additional loss rate of infected biomass $\left(\alpha_{w}\right)$, we assume that this parameter is equal to zero.

The basic reproductive rate $\left(R_{0}\right)$ of a single lesion of P. pachyrhizi, using Eq. A.1 in Appendix A and our empirically estimated parameter values (Table 1), is estimated to be 103.3 lesions. Values for $R_{0}$ for $P$. pachyrhizi on kudzu and soy alone were 2.38 and 103.3, respectively. Note that the difference between the $R_{0}$ estimates for the full system and for soy alone was only 0.0037 . For several parameters $\left(p_{\mathrm{a}}, \varepsilon_{\mathrm{a}}, g, \gamma\right.$, and $S$ ), we found a range of literature values. We used the minimum and maximum values for these parameters to estimate minimum and maximum values for $R_{0}$ of the two host species system to be 0.26 and 667.1 , respectively. While these estimated values are at the scale of lesions rather than fields, they are in concordance with the rapid epidemic progress observed for $P$. pachyrhizi (Christiano and Scherm 2007), and provide a starting point for comparison to future estimates of $R_{0}$ based on data on epidemics in the field.

\section{The seasonal model}

Seasonal forcing can drive host-pathogen dynamics (Altizer et al. 2006, Borer et al. 2007). To examine seasonality with domesticated and wild hosts, we amended the nonseasonal model to incorporate discrete differences in growth $\left(a_{x}\right)$ and loss $\left(b_{x}\right)$ rates of each host species in three seasons. In spring, the domesticated host is not yet planted, but the wild host grows rapidly and the pathogen is transmitted within the wild population. In summer/fall, both hosts grow, and the pathogen is transmitted both within and between host populations. In winter, neither host grows, the pathogen is not transmitted, and susceptible and infected biomass of both host species experiences heavy mortality.

Spring lasts 85 days, from the start of wild host growth at last frost (7 April) until the domesticated host is planted (30 June). The initial local densities of susceptible $\left(S_{\mathrm{w}}\right)$ and infected $\left(I_{\mathrm{w}}\right)$ wild host biomass 


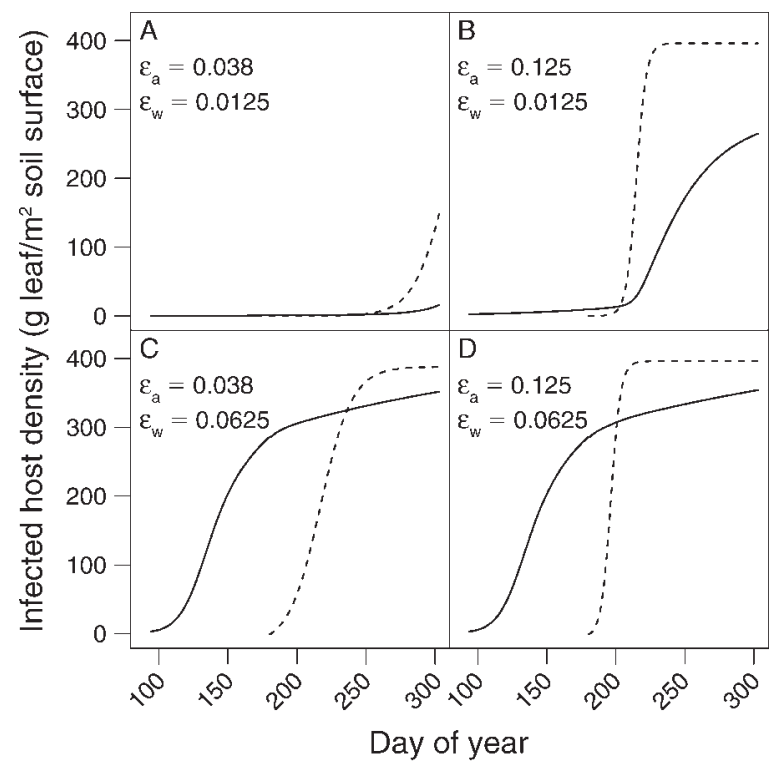

FIG. 1. Predicted seasonal epidemic progress of Asian soybean rust in domesticated (i.e., agricultural; dashed line) and wild (solid line) host populations, across four managed landscapes (A-D) varying in the abundances of a domesticated species (soybean, Glycine max) and wild host species (kudzu, Pueraria montana var. lobata). Their proportional landscape abundances are represented by $\varepsilon_{\mathrm{a}}$ and $\varepsilon_{\mathrm{w}}$, respectively. Density of infected host plants is measured as leaf biomass per square meter of soil surface. Of the pathogen (rust fungus Phakopsora pachyrhizi) population, $1 \%$ successfully overwinter (day $<94)$ on surviving wild hosts. Wild host spring leaf flush occurs at day 94 (7 April), domesticated hosts are planted at day 180 (30 June), and wild host leaves freeze and die at day 303 (30 October). Epidemic progress is driven by the host species with greater landscape abundance.

are determined by winter survivorship from the previous year. Change in infected biomass follows Eq. 1d, while we modify Eq. 1c to be

$$
\frac{d S_{\mathrm{w}}}{d t}=G\left(1-\frac{N_{\mathrm{w}}}{K_{\mathrm{w}}}\right)-b_{\mathrm{w}} S_{\mathrm{w}}-\lambda_{\mathrm{w}} S_{\mathrm{w}} .
$$

This equation simulates spring leaf flush using nutrients and energy from root stocks. The growth rate, $G$, was set to $2704 \mathrm{~g} \cdot \mathrm{m}^{-2} \cdot \mathrm{d}^{-1}$ to ensure that the wild host reaches carrying capacity at the end of the spring. The domesticated host has initial local density $\left(N_{\mathrm{a}}\right)$, growth rate $\left(a_{\mathrm{a}}\right)$, and loss rate $\left(b_{\mathrm{a}}\right)$ all equal to zero.

Summer/fall lasts 122 days, from 1 July until the first freeze kills foliage of both hosts (30 October). The wild host has initial local densities of susceptible $\left(S_{\mathrm{w}}\right)$ and infected $\left(I_{\mathrm{W}}\right)$ biomass equal to those reached at the end of spring. The domesticated host has initial local density of susceptible biomass $\left(S_{\mathrm{a}}\right)$ of $400 \mathrm{~g} / \mathrm{m}^{2}$ and initial local density of infected biomass $\left(I_{\mathrm{a}}\right)$ of zero. Growth and loss rates of each host are the same as in the nonseasonal model (Table 1).

Winter lasts 158 days, from first to last freeze, but all dynamics are assumed to occur in one discrete step. The domesticated host has no winter survivorship, so its initial local density $\left(N_{\mathrm{a}}\right)$ is set to zero. The wild host has initial local densities of susceptible $\left(S_{\mathrm{w}}\right)$ and infected $\left(I_{\mathrm{w}}\right)$ biomass equal to those reached at the end of summer/ fall. Its growth rate $\left(a_{\mathrm{w}}\right)$ and loss rate $\left(b_{\mathrm{w}}\right)$ are both equal to zero, as is the transmission coefficient $\left(\beta_{w w}\right)$. Winter survivorship is simulated by instantly reducing the local densities of susceptible $\left(S_{\mathrm{w}}\right)$ and infected $\left(I_{\mathrm{w}}\right)$ wild host biomass to a fixed proportion of their initial values. The same proportion is applied to both susceptible and infected biomass. By varying the winter survivorship of the wild host between zero and 0.10 , we examine its role as a source of primary inoculum.

Unless otherwise stated, parameter values are the same as for the nonseasonal model (Table 1). We initialize the wild host in the first year with $1 \mathrm{~g} / \mathrm{m}^{2}$ and one fungal lesion, run the model for 20 years to reach an apparent equilibrium, then show the results from the 21 st season.

\section{Simulating dynamics of the models}

To examine the consequence of variation in winter survivorship of the pathogen for epidemic progress, we used the seasonal model to simulate epidemics for a range of parameter values. To examine the sensitivity of model predictions to ecologically important parameters other than winter survivorship of the pathogen, we simulated the dynamics of the nonseasonal model for combinations of parameter values. For both models, results shown are for epidemics starting with a single infection (lesion) in the wild host population; results were similar when initiated in the domesticated host. We chiefly show results in terms of the time required for half of the domesticated population to become infected. This is an inverse measure of the rate of epidemic progress, commonly calculated from sequential empirical observations of infection intensity or prevalence (e.g., Christiano and Scherm 2007). Time to half infection allows application to the economic threshold for plant pest management, which is the pathogen density at which growers need to take action to manage a growing epidemic (e.g., by spraying fungicide) in order to prevent economic injury (Pedigo et al. 1986). For Asian soybean rust in the United States, the economic threshold is currently defined as a single lesion in an adjacent county, although its application may depend on farmer perceptions of risk (Roberts et al. 2006).

\section{RESUlts}

\section{Seasonal model}

We used the seasonal model to predict epidemic progress over a full growing season across four landscapes varying in host species composition (Fig. 1). Epidemic progress is driven chiefly by the host species with greater landscape abundance. In landscapes with low abundance of the wild host species, the pathogen is transmitted at a low rate within the wild host populations, resulting in very slow epidemic progress 
until the domesticated (i.e., agricultural) host is planted across the landscape. If the domesticated host is also at low landscape abundance, epidemic progress then begins to accelerate, but very gradually, first in the domesticated host, then in the wild host (Fig. 1A). If the domesticated host is at higher landscape abundance, rapid transmission between domesticated hosts results in rapid epidemic progress. Buildup of pathogen inoculum on the domesticated host then accelerates disease progress in the wild host, but lags behind the domesticated host (Fig. 1B). In landscapes with high abundance of the wild host species, epidemic progress occurs prior to planting of the domesticated host. Planting of the domesticated host has little impact on epidemic progress in the wild host. Even if the domesticated host is at lower abundance in the landscape than the wild host, transmission from the wild host still results in rapid epidemic progress in the domesticated host (Fig. 1C). Epidemic progress is even more rapid when the domesticated host is planted at higher landscape abundance (Fig. 1D).

Our model predicts that, in regions where a pathogen with a high transmission rate can overwinter on a wild host, the wild host will provide a very potent source of primary inoculum. Epidemic progress in the domesticated population was rapid, and largely insensitive to the winter survivorship of the wild host (Fig. 2). Only in landscapes where both the domesticated and wild host were at very low abundance did decreases in winter survivorship substantially slow epidemic progress in the domesticated host. These results imply that successfully managing epidemics of a highly transmissible pathogen by reducing local densities of the overwintering host would require its near total eradication.

\section{Nonseasonal model}

In simulations, landscape abundance of the wild host $\left(\varepsilon_{\mathrm{w}}\right)$ generally had little effect on epidemic progress in the domesticated host (Fig. 3A). Only at low domesticated host landscape abundances $\left(\varepsilon_{\mathrm{a}}<5 \%\right)$ did wild host landscape abundance have a detectable effect on epidemic progress in the domesticated host. The landscape dominance of the domesticated host strongly affected epidemic progress. These results suggest that a domesticated host will drive epidemic progress in landscapes where it is much more widespread than a wild host, but a wild host may also be influential where the domesticated and wild host are of similar abundance in the landscape. The rate of spore production on the wild host $\left(p_{\mathrm{w}}\right)$ had little effect on domesticated host epidemic progress (Fig. 3B), even when increased sevenfold. The spore production rate on the domesticated host $\left(p_{\mathrm{a}}\right)$ strongly affected epidemic progress. However, over their ranges of variation, epidemic progress was more sensitive to landscape abundance than to rate of spore production.

The fraction of pathogen spores that escape the plant canopy in which they were produced (l) may limit

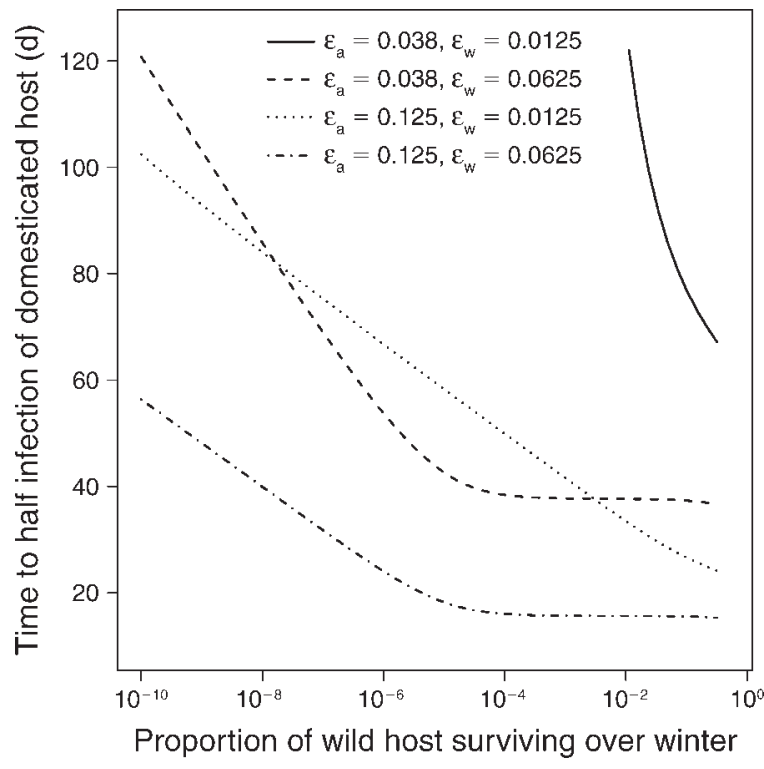

FIG. 2. Predicted time (in days) until half of the domesticated (i.e., agricultural) host population is infected by Asian soybean rust, as a function of winter survivorship (the proportion of the wild host population surviving over the winter). Time to half infection is the inverse of the rate of epidemic progress. As wild host winter survivorship decreases, epidemic progress in the domesticated population slows. Decreasing the landscape abundance of either the domesticated $\left(\varepsilon_{\mathrm{a}}\right)$ or the wild $\left(\varepsilon_{\mathrm{w}}\right)$ host increased sensitivity to winter survivorship. Except when both hosts were at very low landscape abundance, even extremely low wild host winter survivorship (e.g., $10^{-5}$ ) was sufficient to start rapid epidemics.

transmission between patches, and thus between host species restricted to different patch types. Decreasing spore escape to very low rates may prevent pathogen spillover and slow epidemic progress. Indeed, when both hosts were present in the landscape, our model predicted time to half infection in each host to be minimized at an intermediate rate of spore escape from the canopy (Fig. 4). This effect of spillover was much stronger on the wild host than on the domesticated host. Increasing spore escape to high rates is predicted to slow the epidemic in both host populations because increasing numbers of spores are lost to UV radiation. Because spillover is not possible for either host in isolation, increasing spore escape in landscapes including only one host species monotonically slowed epidemic progress (results not shown).

To examine the long-term impact of pathogen infection on wild host local density we assumed that the domesticated host was managed to keep equilibrium disease severity (percentage of leaf biomass infected) at a moderate level (1-30\%), and observed the effect of varying two components of pathogen virulence/aggressiveness (spore production rate, $p_{\mathrm{w}}$, and the loss rate of infected host tissue, $\alpha_{\mathrm{w}}$ ) on wild host population dynamics. While negative impacts on kudzu have not been documented, $P$. pachyrhizi also infects numerous 

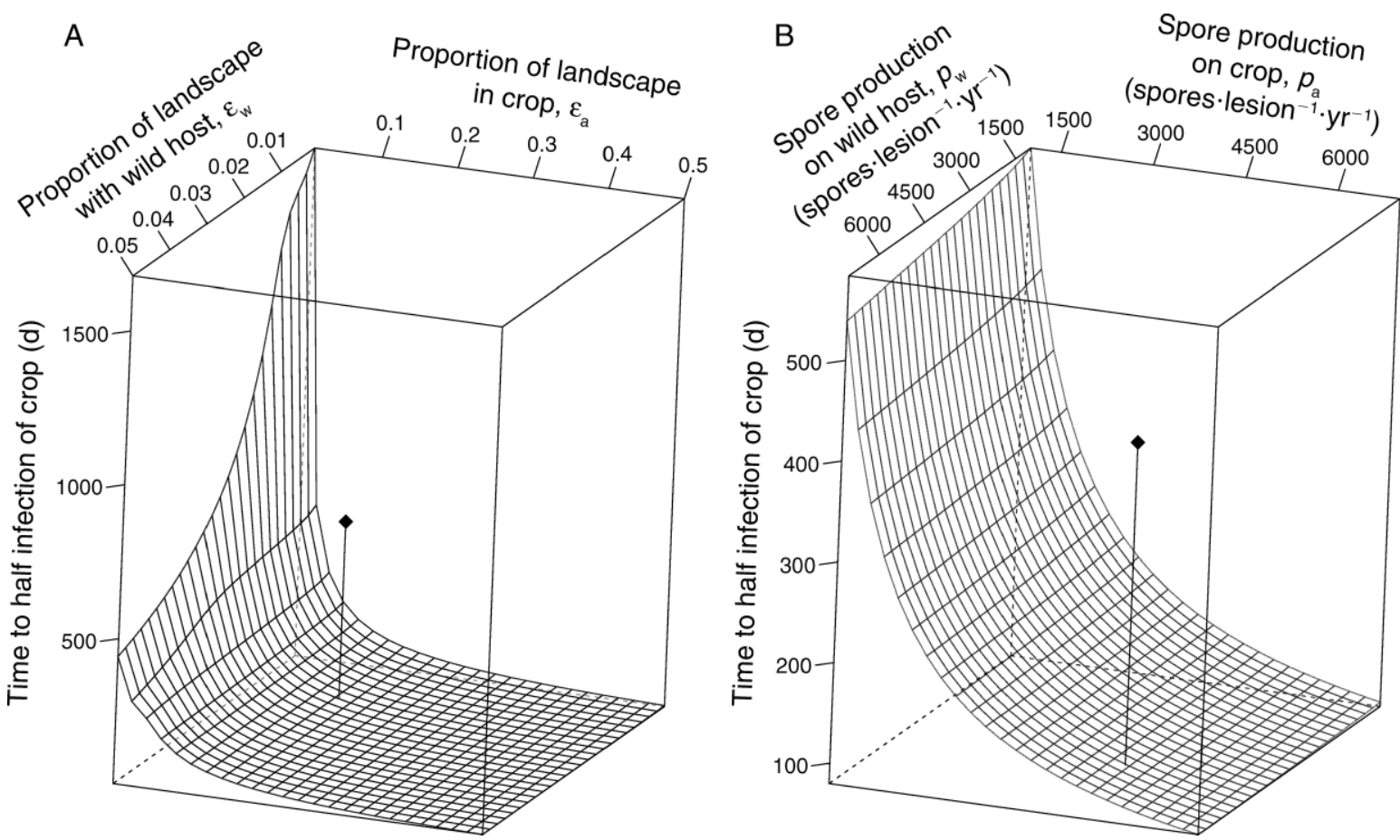

FIG. 3. Predicted time (in days) until half the domesticated host population is infected, as a function of (A) the proportional landscape abundance of each host, and (B) pathogen spore production ( $p$ ) on each host (in spores per lesion per year). Time to half infection is the inverse of the rate of epidemic progress. Epidemic progress is most sensitive to variation in domesticated host landscape abundance. Note that the $z$-axis scale (time to half infection) differs between (A) and (B). Pins indicate the empirically estimated parameter values used in other simulations (Table 1).

other wild legume species (Bonde et al. 2008, Slaminko et al. 2008), and negative impacts of pathogens on wild hosts are common (Gilbert 2002). We varied the additional loss rate of infected wild hosts $\left(\alpha_{\mathrm{w}}\right)$ from zero to $3.5 / t$ to include the modeled growth rate of healthy kudzu $(2.5 / t)$.

Greater wild host loss rate to infection, greater wild host spore production rate, and greater disease severity in the domesticated host were predicted to jointly decrease wild host local population density (Fig. 5AC). When the domesticated host was managed for low disease severity $(1 \%)$, and wild host spore production rate was not at the very low end, higher wild host loss rate to infection was predicted to increase wild host local density (Fig. 5B, C). A closer look at the basis for this apparent paradox reveals that, as the loss rate to infection is increased, the local density of infected biomass decreases, and the local density of healthy biomass increases (Appendix B). At high loss rates to infection, total spore production on the wild host is lowered by the rapid death of infected tissue. This lowers the force of infection, leading to a higher equilibrium of healthy wild host biomass, and thus total wild host biomass. On the other hand, a wild host population (unlike kudzu) with a low intrinsic growth rate may be vulnerable to apparent competition. Analysis of the model shows that pathogen transmission from a domesticated reservoir host can extirpate a wild host with a low intrinsic growth rate (Appendix C). The exact conditions give a nearly quadratic relationship between intrinsic growth rate and force of infection, suggesting that wild host populations will be more responsive to changes in force of infection than intrinsic rate of growth.

\section{Discussion}

\section{Epidemics across landscapes}

Our study indicates that epidemics of airborne pathogens in landscapes including both wild and domesticated (e.g., agricultural) hosts are chiefly driven by the host species that is at greater abundance across the landscape. Only where both host species were at low abundances did seasonal epidemics fail to occur. When either host species was at high landscape abundance, epidemics occurred in both host species. Epidemics in hosts at low landscape abundance were triggered by spillover from epidemics in the host at higher landscape abundance. This provides a theoretical underpinning for empirical studies on a wide range of pathogens and both plant and animal hosts that have led to the same general conclusion (Gilbert and Hubbell 1996, Daszak et al. 2000, Power and Mitchell 2004).

With respect to Asian soybean rust, our simulations examined scenarios of domesticated and wild host abundances relevant to a variety of landscapes in the 
southeastern United States. Regional persistence of Phakopsora pachyrhizi requires living wild host tissue during winter (Isard et al. 2004, Pivonia and Yang 2004). In this region, P. pachyrhizi is only known to overwinter where kudzu is more abundant than soybeans, south of the soybean growing regions (Pivonia and Yang 2004, Jurick et al. 2008). Elsewhere, soybeans are more abundant than kudzu. While $P$. pachyrhizi does not currently overwinter in soybeandominated landscapes, it infects kudzu in these areas, likely via long-distance dispersal from its overwintering refugia. Like overwintering (Jurick et al. 2008), longdistance dispersal produces only a small initial inoculum source (Christiano and Scherm 2007). Nonetheless, this limited inoculum starts epidemics in the domesticated host (Christiano and Scherm 2007), similar to our model predictions for overwintering inoculum. Climate warming may allow $P$. pachyrhizi to overwinter further north. While this would pose a more consistent threat to soybean production, our results suggest that it would not lead to qualitatively different dynamics than those currently resulting from annual long-distance dispersal.

Our model predictions closely match recently reported data on epidemic progress of $P$. pachyrhizi in the southeastern United States (Christiano and Scherm 2007). In both 2005 and 2006, a small number of cases of infected kudzu populations were reported from early in the calendar year. This number grew slowly (in 2005) or stayed nearly constant (in 2006) until the start of the main soybean season (Christiano and Scherm 2007: Fig. 1B). Subsequently in both years, the number of reported cases in soybean increased rapidly until the end of the growing season (Christiano and Scherm 2007: Fig. 1C). After the initiation of the epidemic in soybean (presumed to result from inoculum on kudzu), there was a lag time of 50-75 days before a rapid increase in reported cases in kudzu (Christiano and Scherm 2007: Fig. 1B). The seasonal dynamics of our model mirror these patterns observed in the field. Of particular note is the rapid epidemic progress in the domesticated host immediately after planting, with a marked lag time prior to similar epidemic progress in the wild host. Our model shows that these dynamics can be explained by seasonal shifts in transmission, with initial transmission from the wild host to the domesticated host, amplification by the domesticated host, then spillover to the wild host. What is different in our model is that it assumes that the pathogen overwinters locally on the wild host, whereas kudzu does not currently overwinter in soybean growing regions, so initial inoculum on kudzu results from longdistance dispersal (Krupa et al. 2006, Pan et al. 2006, Isard et al. 2007). Our model suggests that local overwintering on the wild host and long-distance pathogen dispersal before susceptible domesticated hosts are present can lead to epidemics in a late-planted domesticated host. These results highlight the role of the wild host as a source of initial inoculum, and the role of

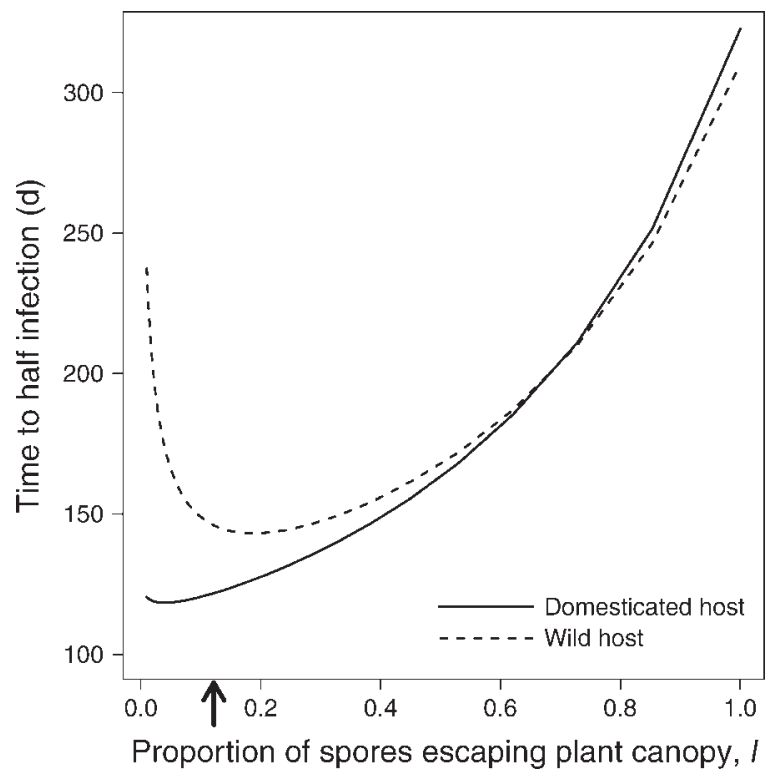

FIG. 4. Predicted time (in days) until half of the domesticated (solid line) or wild (dashed line) host population is infected, as a function of the fraction of spores escaping into the atmosphere from the host canopy of the landscape patch in which they are produced. Time to half infection is the inverse of the rate of epidemic progress. High escape rates slow epidemic progress by increasing spore losses to UV radiation. Very low escape rates slow epidemic progress by preventing pathogen spillover. The arrow indicates the empirically estimated parameter value used in other simulations (Table 1).

the domesticated host as an amplifying host during the growing season. Each host functions as a reservoir, but in different seasons.

\section{Epidemics in landscapes dominated by the domesticated host}

In most managed landscapes, the domesticated host will be much more abundant than the wild host. Here, while epidemics are driven chiefly by the abundance of the domesticated host, they also require the presence of the wild host, to serve as an overwintering source of pathogen inoculum. However, our results suggest that for the type of pathogen that is of greatest concern (i.e., those with a high transmission rate) very low landscape abundances of the wild host, located in landscape patches separate from the domesticated host, provide sufficient overwintering inoculum to start rapidly progressing epidemics in the growing season. Epidemic progress was generally insensitive to the spore production rate of the pathogen on infected wild host tissue, and was only sensitive to the landscape abundance of the wild host when the domesticated host was at very low landscape abundance. Because the biological assumptions of our model about the two host species, other than their landscape abundance, were very similar, our model supports the general hypothesis that the high landscape abundance of domesticated species is a chief cause of disease epidemics and pathogen spillover 


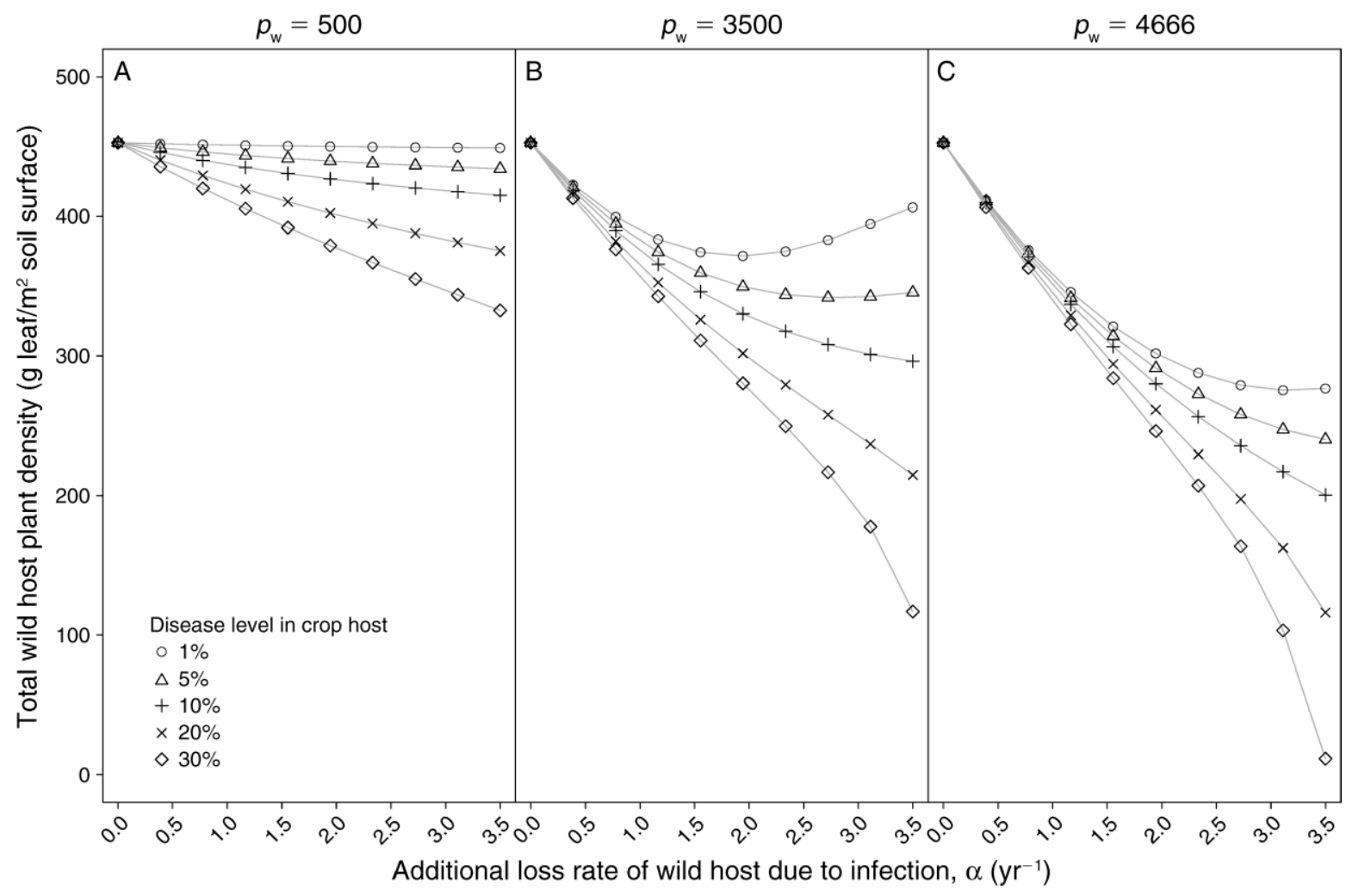

FIG. 5. Predicted change in wild host local density as its loss rate to infection increases. Spore production rate on the wild host ( $p_{\mathrm{w}}$ ) was (A) 500, (B) 3500, or (C) 4666 spores per lesion per year. To simulate management of the pathogen, infected domesticated host local density was held constant at each of five levels, represented by different lines and symbols in each panel. The $y$-axis units are grams of total host leaf biomass (i.e., the sum of infected and uninfected host leaf biomass) per square meter of soil surface. Disease level is the percentage of domesticated host plant biomass that was infected. The additional loss rate is the rate of mortality attributed solely to infection, in addition to baseline mortality, expressed per year.

(Gilbert and Hubbell 1996, Daszak et al. 2000, Power and Mitchell 2004). As well as the high landscape abundance of domesticated hosts, past empirical studies and reviews have suggested that the overwintering ability of wild hosts (Pivonia and Yang 2004, Plantegenest et al. 2007) is a chief control on pathogens transmitted between domesticated and wild host species. Our results provide a general, quantitative analysis of how these two factors jointly control epidemics of multihost pathogens.

When domesticated and wild hosts occur in separate patches within a landscape, pathogen dispersal is necessary for pathogen spillover. On the other hand, pathogen dispersal reduces the inoculum for withinpatch transmission. In our model, the escape of pathogen spores from the plant canopy into the atmosphere is a key component of pathogen dispersal. In landscapes including both host species, epidemic progress was predicted to be maximized at an intermediate rate of spore escape. This suggests that variation in rate of spore escape (e.g., due to changing meteorological conditions or canopy phenology; Aylor 2003) may influence epidemic progress. These results also emphasize that transmission between landscape patches is sensitive to contact rates of infected hosts, whether dispersal among landscape patches is by hosts or pathogens (Dobson and Meagher 1996, McCallum and Dobson 2002, McCallum et al. 2005).

Our results suggest that prevention of epidemics by reduction of wild host local densities would require intensive management. Such efforts with other rusts have required decades of initial effort followed by vigilant monitoring (Roelfs 1982, Peterson et al. 2005). The biology of $P$. pachyrhizi and kudzu (Forseth and Innis 2004) may make its eradication even more challenging. Our results provide better prospects for the management of pathogen spillover from domesticated hosts to wild host populations of conservation concern. For example, P. pachyrhizi not only infects kudzu, but also plants in at least 33 genera of Fabaceae found in the United States (Bonde et al. 2008, Slaminko et al. 2008). Five taxa are federally listed as threatened or endangered, and are present in states with significant soybean production (Missouri Botanical Garden 2008). P. pachyrhizi thus presents a potential threat to native legume populations. It is likely that these native populations would be unable to sustain $P$. pachyrhizi epidemics in isolation. Nonetheless, heavy spillover from 
crop fields could decrease their local densities, or even drive them extinct. Apparent competition resulting from pathogen spillover has been implicated in declines of native plant and wildlife populations (Daszak et al. 2000, Borer et al. 2007). Our results predict that this threat can be greatly reduced by management of pathogen infection in domesticated populations. In fact, this may be more effective than directly enhancing the reproduction and survivorship of the wild host. The clear economic incentive to manage pathogen infection in domesticated host populations will have additional "halo" benefits for native host populations.

\section{AcKNowledgments}

A. M. Fabiszewski developed the model, analyzed the model, obtained empirical estimates of parameter values, performed the simulations, wrote the first manuscript draft as her B.S. honors thesis, and edited all drafts. J. Umbanhower coconceived the project, developed and analyzed the model, performed the simulations, produced the figures, and edited all drafts. C. E. Mitchell co-conceived the project, facilitated the gathering of contributors, provided funding, edited all drafts, prepared the final version of the manuscript, and is the guarantor for the integrity of the article as a whole. We thank M. A. Barrett, D. Crawford-Brown, J. P. Cronin, M. E. Welsh, and two anonymous referees for reviews that greatly improved the manuscript. This research was supported by funding from the University of North Carolina at Chapel Hill.

\section{Literature Cited}

Altizer, S., A. Dobson, P. Hosseini, P. Hudson, M. Pascual, and P. Rohani. 2006. Seasonality and the dynamics of infectious diseases. Ecology Letters 9:467-484.

Anderson, P. K., A. A. Cunningham, N. G. Patel, F. J. Morales, P. R. Epstein, and P. Daszak. 2004. Emerging infectious diseases of plants: pathogen pollution, climate change and agrotechnology drivers. Trends in Ecology and Evolution 19:535-544.

Aylor, D. E. 2003. Spread of plant disease on a continental scale: role of aerial dispersal of pathogens. Ecology 84:1989-1997.

Ball, R. A., L. C. Purcell, and E. D. Vories. 2000. Optimizing soybean plant population for a short-season production system in the southern USA. Crop Science 40:757-764.

Bonde, M. R., S. E. Nester, D. K. Berner, R. D. Frederick, W. F. Moore, and S. Little. 2008. Comparative susceptibilities of legume species to infection by Phakopsora pachyrhizi. Plant Disease 92:30-36.

Borer, E. T., P. R. Hosseini, E. W. Seabloom, and A. P. Dobson. 2007. Pathogen-induced reversal of native dominance in a grassland community. Proceedings of the National Academy of Sciences (USA) 104:5473-5478.

Christiano, R. S. C., and H. Scherm. 2007. Quantitative aspects of the spread of Asian soybean rust in the southeastern United States, 2005 to 2006. Phytopathology 97:1428-1433.

Condeso, T. E., and R. K. Meentemeyer. 2007. Effects of landscape heterogeneity on the emerging forest disease sudden oak death. Journal of Ecology 95:364-375.

Daszak, P., A. A. Cunningham, and A. D. Hyatt. 2000. Emerging infectious diseases of wildlife - threats to biodiversity and human health. Science 287:443-449.

Diekmann, O., J. A. P. Heesterbeek, and J. A. J. Metz. 1990. On the definition and the computation of the basic reproduction ratio $R_{0}$ in models for infectious diseases in heterogeneous populations. Journal of Mathematical Biology 28:365-382.

Dobson, A. 2004. Population dynamics of pathogens with multiple host species. American Naturalist 164:S64-S78.
Dobson, A., and M. Meagher. 1996. The population dynamics of brucellosis in the Yellowstone National Park. Ecology 77: $1026-1036$.

Forseth, I. N., and A. F. Innis. 2004. Kudzu (Pueraria montana): History, physiology, and ecology combine to make a major ecosystem threat. Critical Reviews in Plant Sciences 23:401-413.

Gilbert, G. S. 2002. Evolutionary ecology of plant diseases in natural ecosystems. Annual Review of Phytopathology 40: $13-43$.

Gilbert, G. S., and S. P. Hubbell. 1996. Plant diseases and the conservation of tropical forests. BioScience 46:98-106.

Gilbert, G. S., and C. O. Webb. 2007. Phylogenetic signal in plant pathogen-host range. Proceedings of the National Academy of Sciences (USA) 104:4979-4983.

Gog, J., R. Woodroffe, and J. Swinton. 2002. Disease in endangered metapopulations: the importance of alternative hosts. Proceedings of the Royal Society B 269:671-676.

Holt, R. D., and J. Pickering. 1985. Infectious disease and species coexistence: a model of Lotka-Volterra form. American Naturalist 126:196-211.

Hudson, P., and J. Greenman. 1998. Competition mediated by parasites: biological and theoretical progress. Trends in Ecology and Evolution 13:387-390.

Isard, S. A., C. Main, T. Keever, R. Magarey, S. Redlin, and J. M. Russo. 2004. Weather-based assessment of soybean rust threat to North America: first year report to APHIS. USDA, Animal and Plant Health Inspection Service, Washington, D.C., USA.

Isard, S. A., J. M. Russo, and A. Ariatti. 2007. The integrated aerobiology modeling system applied to the spread of soybean rust into the Ohio River valley during September 2006. Aerobiologia 23:271-282.

Jurick, W. M., D. F. Narvaez, M. M. Brennan, C. L. Harmon, J. J. Marois, D. L. Wright, and P. F. Harmon. 2008. Winter survival of the soybean rust pathogen, Phakopsora pachyrhi$z i$, in Florida. Plant Disease 92:1551-1558.

Krupa, S., V. Bowersox, R. Claybrooke, C. W. Barnes, L. Szabo, K. Harlin, and J. Kurle. 2006. Introduction of Asian soybean rust urediniospores into the Midwestern United States - a case study. Plant Disease 90:1254-1259.

McCallum, H., and A. Dobson. 2002. Disease, habitat fragmentation and conservation. Proceedings of the Royal Society B 269:2041-2049.

McCallum, H., L. Gerber, and A. Jani. 2005. Does infectious disease influence the efficacy of marine protected areas? A theoretical framework. Journal of Applied Ecology 42:688-698.

Melching, J. S., K. R. Bromfield, and C. H. Kingsolver. 1979. Infection, colonization, and uredospore production on Wayne soybean by four cultures of Phakopsora pachyrhizi, the cause of soybean rust. Phytopathology 69:1262-1265.

Merriam, R. W. 2003. The abundance, distribution and edge associations of six non-indigenous, harmful plants across North Carolina. Journal of the Torrey Botanical Society 130: 283-291.

Missouri Botanical Garden. 2008. Center for plant conservation. 〈http://www.centerforplantconservation.org/ASP/ NationalCollection.asp $\rangle$

National Agricultural Statistics Service (NASS). 2006. Planted acreage report. Report number Cr Pr 2-5 (6-06). USDA, Washington, D.C., USA. 〈www.nass.usda.gov〉

Pan, Z., X. B. Yang, S. Pivonia, L. Xue, R. Pasken, and J. Roads. 2006. Long-term prediction of soybean rust entry into the continental United States. Plant Disease 90:840-846.

Park, S., Z. Y. Chen, A. K. Chanda, R. W. Schneider, and C. A. Hollier. 2008. Viability of Phakopsora pachyrhizi urediniospores under simulated southern Louisiana winter temperature conditions. Plant Disease 92:1456-1462.

Pedigo, L. P., S. H. Hutchins, and L. G. Higley. 1986. Economic injury levels in theory and practice. Annual Review of Entomology 31:341-368. 
Peterson, P. D., K. J. Leonard, J. D. Miller, R. J. Laudon, and T. B. Sutton. 2005. Prevalence and distribution of common barberry, the alternate host of Puccina graminis, in Minnesota. Plant Disease 89:159-163.

Pivonia, S., and X. B. Yang. 2004. Assessment of the potential year-round establishment of soybean rust throughout the world. Plant Disease 88:523-529.

Pivonia, S., and X. B. Yang. 2006. Relating epidemic progress from a general disease model to seasonal appearance time of rusts in the United States: implications for soybean rust. Phytopathology 96:400-407.

Pivonia, S., X. B. Yang, and Z. Pan. 2005. Assessment of epidemic potential of soybean rust in the United States. Plant Disease 89:678-682.

Plantegenest, M., C. Le May, and F. Fabre. 2007. Landscape epidemiology of plant diseases. Journal of the Royal Society Interface 4:963-972.

Power, A. G., and C. E. Mitchell. 2004. Pathogen spillover in disease epidemics. American Naturalist 164:S79-S89.

Real, L. A., and R. Biek. 2007. Spatial dynamics and genetics of infectious diseases on heterogeneous landscapes. Journal of the Royal Society Interface 4:935-948.

Riley, S. 2007. Large-scale spatial-transmission models of infectious disease. Science 316:1298-1301.

Roberts, M. J., D. Schimmelpfennig, E. Ashley, and M. Livingston. 2006. The value of plant disease early-warning systems: a case study of USDA's soybean rust coordinated framework. USDA, Economic Research Service Report No. 18. 〈http://www.ers.usda.gov/publications/err18/err18fm. pdf $\rangle$

Roelfs, A. P. 1982. Effects of barberry eradication on stem rust in the United States. Plant Disease 66:177-181.
Sasek, T. W., and B. R. Strain. 1988. Effects of carbon dioxide enrichment on the growth and morphology of kudzu (Puerara lobata). Weed Science 36:28-36.

Schnepf, R. 2005. Asian soybean rust: background and issues. Congressional Research Service. 〈http://lugar.senate.gov/ reports/RL32225_soy.pdf $\rangle$

Slaminko, T. L., M. R. Miles, R. D. Frederick, M. R. Bonde, and G. L. Hartman. 2008. New legume hosts of Phakopsora pachyrhizi based on greenhouse evaluations. Plant Disease 92:767-771.

Toth, S. R. J., J. R. Baker, S. R. Koenning, J. Van Duyn, and A. C. York. 2005. Crop profiles for soybeans in North Carolina. USDA, Integrated Pest Management Centers Information System. 〈http://www.ipmcenters.org/CropProfiles/docs/ NCsoybeans.html $\rangle$

Tsugawa, H., K. Nobuyoshi, T. W. Sasek, T. Takahashi, and K. Yamamoto. 1993. Dry matter production and leaf area expansion of the current year's canopy in a natural kudzu (Pueraria lobata Ohwi) stand, established in a field left abandoned for about 15 years. Journal of Japanese Society of Grassland Science 38:440-452.

U.S. Census Bureau. 2002. County and city data book: 2000. 〈www.census.gov/prod/www/ccdb.html〉

Woodroffe, R., et al. 2006. Culling and cattle controls influence tuberculosis risk for badgers. Proceedings of the National Academy of Sciences (USA) 103:14713-14717.

Yang, X. B. 1995. Assessment and management of the risk of soybean rust. Proceedings of the soybean rust workshop, 911 August, 1995. J. B. Sinclair and G. L. Hartman, editors. National Soybean Research Laboratory, Urbana, Illinois, USA.

\section{APPENDIX A}

Mathematical derivations of $R_{0}$ (the basic reproductive rate of the pathogen) for the nonseasonal model (Ecological Archives A020-017-A1).

\section{APPENDIX B}

A figure showing how increased loss rates due to pathogen infection can increase the total local density of a wild host population (Ecological Archives A020-017-A2).

\section{APPENDIX C}

A mathematical derivation of the conditions under which pathogen spillover from a domesticated host population can extirpate a wild host population (Ecological Archives A020-017-A3).

\section{APPENDIX D}

Methods by which empirical values (and/or ranges of variation) for the model parameters were obtained (Ecological Archives A020-017-A4). 


\section{Ecological Archives A020-017-A1}

\section{Anna M. Fabiszewski, James Umbanhowar, and Charles E. Mitchell. 2010. Modeling landscape- scale pathogen spillover between domesticated and wild hosts: Asian soybean rust and kudzu. Ecological Applications 20:582-592.}

Appendix A. Mathematical derivations of $R_{0}$ (the basic reproductive rate of the pathogen) for the nonseasonal model.

We calculated $R_{0}$ for the full model following the analysis of Dobson (2004), who considered a special case of the general model derived by Diekmann et al. (1990). First, we obtained the "next generation matrix" (G; Dobson 2004) for our model (Eq. 1):

$$
\mathbf{G}=\left[\begin{array}{cc}
\frac{\beta_{a a} N_{a}}{\alpha_{a}+b_{a}} & \frac{\beta_{a w} N_{a}}{\alpha_{a}+b_{a}} \\
\frac{\beta_{w a} K_{w}\left(1-b_{w} / a_{w}\right)}{\alpha_{w}+b_{w}} & \frac{\beta_{w w} K_{w}\left(1-b_{w} / a_{w}\right)}{\alpha_{w}+b_{w}}
\end{array}\right] .
$$

The largest eigenvalue of $\mathbf{G}$ is the $R_{0}$ for the system with two host species. Using the formula for $\beta_{\mathrm{ii}}$ in Eq. 3 yields the following expression:

$$
\begin{aligned}
R_{0}= & \frac{\beta_{a a} N_{a}}{2\left(\alpha_{a}+b_{a}\right)}+\frac{\beta_{w w} K_{w}\left(1-b_{w} / a_{w}\right)}{2\left(\alpha_{w}+b_{w}\right)}+ \\
& \sqrt{\left(\frac{\beta_{a a} N_{a}}{2\left(\alpha_{a}+b_{a}\right)}\right)^{2}+\left(\frac{\beta_{w w} K_{w}\left(1-b_{w} / a_{w}\right)}{2\left(\alpha_{w}+b_{w}\right)}\right)^{2}+\frac{N_{a} K_{w}\left(1-b_{w} / a_{w}\right)\left(2 \beta_{a w} \beta_{w a}-\beta_{w w} \beta_{a a}\right)}{2\left(\alpha_{a}+b_{a}\right)\left(\alpha_{w}+b_{w}\right)}} .
\end{aligned}
$$




$$
R_{0 a}=\frac{\beta_{a a} N_{a}}{\left(\alpha_{a}+b_{a}\right)}
$$

and

$$
R_{0 w}=\frac{\beta_{w w} K_{w}\left(1-b_{w} / a_{w}\right)}{\left(\alpha_{w}+b_{w}\right)}
$$

\section{LITERATURE CITED}

Diekmann, O., J. A. P. Heesterbeek, and J. A. J. Metz. 1990. On the definition and the computation of the basic reproduction ratio $R_{0}$ in models for infectious-diseases in heterogeneous populations. Journal of Mathematical Biology 28:365-382.

Dobson, A. 2004. Population dynamics of pathogens with multiple host species. The American Naturalist 164:S64-S78.

\section{[Back to A020-017]}


Anna M. Fabiszewski, James Umbanhowar, and Charles E. Mitchell. 2010. Modeling landscapescale pathogen spillover between domesticated and wild hosts: Asian soybean rust and kudzu. Ecological Applications 20:582-592.

Appendix B. A figure showing how increased loss rates due to pathogen infection can increase the total local density of a wild host population.

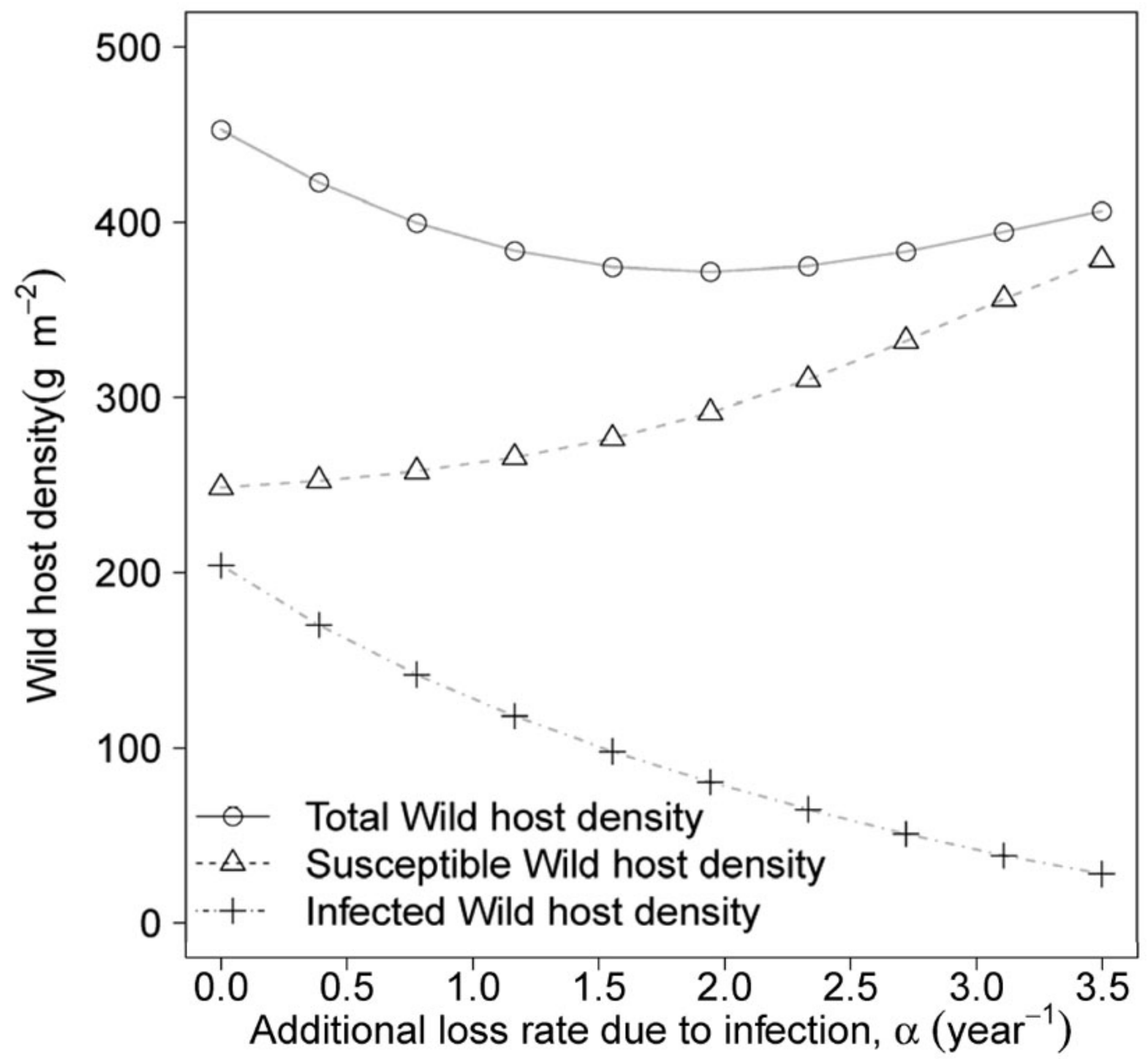


FIG. B1. Change in wild host local density (total, susceptible, and infected) as the loss rate to infection is increased. The model was run with infected domesticated host local density fixed at $4 \mathrm{~g} / \mathrm{m}^{2}$ ( $1 \%$ of total domesticated host local density), and spore production on the wild host at a rate of 3500 spores per lesion per year. As loss to infection increases, infected wild host local density decreases, causing the force of infection to also decrease. Susceptible wild host local density can increase in compensation because total wild host local density is below carrying capacity.

[Back to A020-017] 


\section{Ecological Archives A020-017-A3}

\section{Anna M. Fabiszewski, James Umbanhowar, and Charles E. Mitchell. 2010. Modeling landscape- scale pathogen spillover between domesticated and wild hosts: Asian soybean rust and kudzu. Ecological Applications 20:582-592.}

Appendix C. A mathematical derivation of the conditions under which pathogen spillover from a domesticated host population can extirpate a wild host population.

We derive the conditions under which spillover from a domesticated host, managed for reduced pathogen infection, causes the deterministic extinction of a wild host population. The assumption that the domesticated host is managed for reduced pathogen infection means that there is both a fixed local population density of the domesticated host, and a fixed proportion of that host that is infected, i.e., $I_{a}=c N_{a}$. This assumption eliminates variables and reduces the number of equations in the model to the following two:

$$
\begin{aligned}
& \left.\frac{d S_{w}}{d t}=\left[\delta_{w} I_{w}+a_{w} S_{w}\right] 1-N_{w} / K_{w}\right)-b_{w} S_{w}-\lambda_{w} S_{w} \\
& \frac{d I_{w}}{d t}=\lambda_{w} S_{w}-\left(\alpha_{w}+b_{w}\right) I_{w}
\end{aligned}
$$

The analysis will find the parameter values where the trivial equilibrium of this reduced model $\left(S_{w}=I_{w}=0\right)$ is stable, but the growth rate of the wild population in the absence of infection is positive, i.e., $a_{w}-b_{w}>0$.

One more assumption facilitates the analysis. We assume that the pathogen propagules infecting wild hosts come from the managed domesticated population. This assumption is valid because the analysis is done at small population sizes.

Given this assumption, the force of infection on the wild host is given by:

$$
\lambda=\frac{I_{a} p_{a} d_{a}\left(1-l_{a}+l_{a} m\right) \varepsilon_{a} g_{w} \gamma_{w} A_{w}}{\left(1+\gamma_{w} N_{W}\right) A_{a}}
$$


For ease of reading and writing, we use the following substitution:

$$
F=\frac{p_{a} d_{a}\left(1-l_{a}+l_{a} m\right) \varepsilon_{a} g_{w} \gamma_{w} A_{w}}{A_{a}}
$$

giving:

$$
\lambda=\frac{I_{a} F}{\left(1+\gamma_{w} N_{W}\right)}
$$

Eigenvalues for system (A-1) linearized about the trivial equilibrium are:

$$
\delta=\frac{1}{2}\left(a_{w}-2 b_{w}-F I_{a}-\alpha_{w} \pm \sqrt{a_{w}+2 a_{w} F I_{a}+F^{2} I_{a}^{2}+2 a_{w} \alpha_{w}-2 F I_{a} \alpha_{w}+\alpha_{w}}\right)
$$

The trivial equilibrium is stable when the largest eigenvalue is less than zero. This occurs when the portion of the eigenvalue outside the radical is negative and of a greater magnitude than that under the radical, or when the expression under the radical is negative and the expression outside of the radical is negative. If the expression under the radical is negative, then $2 a_{w} F l_{a}-2 F l_{a} \alpha_{w}<0$ and this means that $\alpha_{w}-\alpha_{w}<0$. From this, we conclude that if the expression under the radical is negative, then the expression outside the radical is also negative and the conditions for the stability of the trivial equilibrium are:

$$
\left(a_{w}-2 b_{w}-F I_{a}-\alpha_{w}\right)^{2}>a_{w}+2 a_{w} F I_{a}+F^{2} I_{a}^{2}+2 a_{w} \alpha_{w}-2 F I_{a} \alpha_{w}+\alpha_{w}
$$

which simplifies to: 


$$
a_{w}<F I_{a}+\alpha_{w}+b_{w}+\frac{\left(F^{2} I_{a}^{2}+\alpha_{w}\right)}{2 b_{w}}
$$

This condition can be rewritten in a slightly different form that shows the relationship between the intrinsic rate of increase of the wild population $\left(a_{w}-b_{w}\right)$ and other parameters where deterministic extinction due to spillover occurs:

$$
a_{w}-b_{w}<F I_{a}+\alpha_{w}+\frac{\left(F^{2} I_{a}^{2}+\alpha_{w}\right)}{2 b_{w}}
$$

[Back to A020-017] 


\section{Ecological Archives A020-017-A4}

\section{Anna M. Fabiszewski, James Umbanhowar, and Charles E. Mitchell. 2010. Modeling landscape-scale pathogen spillover between domesticated and wild hosts: Asian soybean rust and kudzu. Ecological Applications 20:582-592.}

Appendix D. Methods by which empirical values (and/or ranges of variation) for the model parameters were obtained.

The model was parameterized using soybean rust (Phakopsora pachyrhizi) as the domesticated host, and kudzu (Pueraria montana var. lobata) as the wild host. We used published studies to estimate values for each parameter (Table 1).

The biomass density of a lesion on a leaf $\left(A_{a}, A_{w}\right)$ converts between units of infected host biomass (g/ $\mathrm{m}^{2}$ ) and lesion number. It is the biomass of a lesion divided by the total leaf area of the host species. Separate studies provided estimates of the area of a $P$. pachyrhizi lesion on soybeans (Marchetti et al. 1975) and kudzu (Carmona et al. 2005). Each area was converted to mass using data on specific leaf area for that host species (Sasek and Strain 1988, Tsugawa et al. 1993, Jiang and Xu 2001, Forseth and Innis 2004). We assumed that leaf area index was equal to one, and therefore that total leaf area was equal to the area of the landscape occupied by the host species. The area of the landscape occupied by each host species was calculated by multiplying the fraction of the landscape occupied by the host species $\left(e_{a}, e_{w}\right)$ by the total area of the landscape, which we defined as $1.8 \times 10^{8} \mathrm{~m}^{2}$.

We estimated the rates of pathogen spore production $\left(p_{i}\right)$, in units of spores per lesion per year, based on experiments that quantified both the total number of spores produced by a $P$. pachyrhizi lesion over its lifetime, and the average lesion lifetime (Melching et al. 1979). We assumed that a "year" is equal to the length of time in a year that the host is able to be infected (i.e. the duration of its annual growing season). For soybeans, this is the duration of the crop season, which is approximately 170 days. For kudzu in North Carolina, this is the frost-free season, an average of 210 days (Perry 1998a, b). These two time estimates were used to calculate the number of pathogen generations that can occur in one year for each host.

The proportion of spores produced assumed to be lost to the soil in the same patch $(1-d)$ was estimated from a study of the wheat leaf rust fungus, Puccinia triticina (Eversmeyer and Kramer 1992). We used data on Puccinia triticina because data on P. pachyrhizi was not available, and Puccinia triticina was found to be broadly similar in biological attributes to P. pachyrhizi (Pivonia and Yang 2006). The success of spores entering the atmosphere varies based on environmental conditions (Zaitao et al. 2007).

We assumed that $12.2 \%$ of $P$. pachyrhizi spores successfully escape into the atmosphere $(l)$, based on a 
field experiment in a closed soybean rust canopy (Zidek et al. 2007). Spores in the atmosphere were assumed to become evenly distributed across the landscape. Net flow of spores in or out of the landscape was assumed to be negligible.

Spore mortality in transport is assumed to come only from UV radiation (Isard et al. 2004). The fraction of surviving spores, $m$, was calculated as a function of total daily incoming solar radiation (Rad) in megajoules $\left(\mathrm{MJm}^{-2}\right)$ using the following equation adapted from Isard (2004):

$\mathrm{m}=\mathrm{e}^{-\mathrm{Rad} / 14.0}$

The incoming solar radiation (Rad) data used is total daily solar radiation data from 1961-1990 (U.S. Department of Energy 2007) averaged over July-November, the growing season of soybeans. While a later study found a linear relationship between fraction of surviving spores and solar radiation (Isard et al. 2006), both the linear and exponential model predict a similar fraction of surviving spores, except at the highest doses of radiation, where the linear model predicts complete extirpation of the spores (Isard et al. 2006).

We estimated the parameter, g, which relates the proportion of $P$. pachyrhizi spores that successfully infect the host to host density, based on another study of Puccinia triticina (Pfleeger and Mundt 1998), for the same reasons as above. The parameter best estimate was an average of six regressions of rust severity versus host density. The assumption was made that the proportion of spores that successfully infect is proportional to rust severity. To fit this assumption, we used data on rust severity taken 4-6 weeks after inoculation to minimize potential for secondary transmission (Pfleeger and Mundt 1998). Data from Blacklow and Incoll (1981) and Wilhelm et al. (2002) were used to convert units from wheat culms to biomass density.

The germination success of $P$. pachyrhizi spores independent of environment $(g)$ was determined from controlled experiments on rates of spore germination on agar (Marchetti et al. 1976, Bonde et al. 2007).

\section{LITERATURE CITED}

Blacklow, W. M., and L. D. Incoll. 1981. Nitrogen Stress of Winter Wheat changed the Determinants of Yield and the Distribution of Nitrogen and Total Dry matter during Grain Filling. Australian Journal of Plant Physiology 8:191-200.

Bonde, M. R., D. K. Berner, S. E. Nester, and R. D. Frederick. 2007. Effects of Temperature on Urediniospore Germination, Germ Tube Growth, and Initiation of Infection in Soybean by Phakopsora Isolates. Phytopathology 97:997-1003.

Carmona, M. A., C. Fortugno, and P. L. Achaval. 2005. Morphologic and pathometric characterization of the Asian soybean rust (Phakopsora pachyrhizi) on Kudzu (Pueraria lobata) in Argentina. Plant Disease 89:1132-1132. 
Eversmeyer, M. G., and C. L. Kramer. 1992. Local dispersal and deposition of fungal spores from a wheat canopy. Grana 31:53-59.

Forseth, I. N., and A. F. Innis. 2004. Kudzu (Pueraria montana): History, physiology, and ecology combine to make a major ecosystem threat. Critical Reviews in Plant Sciences 23:401-413.

Isard, S. A., N. S. Dufault, M. R. Miles, G. L. Hartman, J. M. Russo, E. D. De Wolf, and W. Morel. 2006. The effect of solar irradiance on the mortality of Phakopsora pachyrhizi urediniospores. Plant Disease 90:941-945.

Isard, S. A., S. H. Gage, P. Comtois, and J. M. Russo. 2005. Principles of the atmospheric pathway for invasive species applied to soybean rust. Bioscience 55:851-861.

Jiang, H., and D. Q. Xu. 2001. The cause of the difference in leaf net photosynthetic rate between two soybean cultivars. Photosynthetica 39:453-459.

Marchetti, M. A., J. S. Melching, and K. R. Bromfield. 1976. Effects of temperature and dew period on germination and infection by uredospores of Phakopsora pachyrhizi. Phytopathology 66:461-463.

Marchetti, M. A., F. A. Uecker, and K. R. Bromfield. 1975. Uredial development of Phakopsora pachyrhizi in soybeans. Phytopathology 65:822-823.

Melching, J. S., K. R. Bromfield, and C. H. Kingsolver. 1979. Infection, colonization, and uredospore production on Wayne soybean by 4 cultures of Phakopsora pachyrhizi, the cause of soybean rust. Phytopathology 69:1262-1265.

Perry, K. B. 1998a. Average First Fall Frost Dates for Selected North Carolina Locations. North Carolina State University: Horticultural Information Leaflets.

Perry, K. B. 1998b. Average Last Spring Frost Dates for Selected North Carolina Locations. North Carolina State University: Horticultural Information Leaflets.

Pfleeger, T. G., and C. C. Mundt. 1998. Wheat leaf rust severity as affected by plant density and species proportion in simple communities of wheat and wild oats. Phytopathology 88:708-714.

Pivonia, S., and X. B. Yang. 2006. Relating epidemic progress from a general disease model to seasonal appearance time of rusts in the united states: Implications for soybean rust. Phytopathology 96:400-407.

Sasek, T. W., and B. R. Strain. 1988. Effects of carbon dioxide enrichment on the growth and morphology of kudzu (Puerara lobata). Weed Science 36:28-36. 
Tsugawa, H., K. Nobuyoshi, T. W. Sasek, T. Takahashi, and K. Yamamoto. 1993. Dry matter production and leaf area expansion of the current year's canopy in a natural kudzu (Pueraria lobata Ohwi) stand, established in a field left abandoned for about 15 years. Journal of Japanese Society of Grassland Science 38:440-452.

U.S. Department of Energy. 2007. Averages of Solar Radiation for each month, 1961-1990. Renwable Resource Data Center.

Wilhelm, W. W., G. S. McMaster, and D. M. Harrell. 2002. Nitrogen and dry matter distribution by culm and leaf position at two stages of vegetative growth in winter wheat. Agronomy Journal 94:10781086.

Zaitao, P., D. Andrade, W. Dannevik, and J. M. Zidek. 2007. Modelling soybean rust spore release from infected canopies by turbulence. In 2007 National Soybean Rust Symposium, Louisville, Kentucky.

Zidek, J. M., S. A. Isard, J. J. Marois, and D. Wright. 2007. Phakopsora pachyrhizi urediniospore escape from a soybean canopy. In 2007 National Soybean Rust Symposium. Plant Management Network, Louisville, Kentucky, USA. 